\title{
Effect of Condenser Air Flow on the Performance of Split Air Conditioner
}

\author{
Amr O. Elsayed ${ }^{1, *}$, Abdulrahman S. Hariri ${ }^{1}$ \\ ${ }^{1}$ College of Engineering, University of Dammam, Saudi Arabia \\ * Corresponding author. Tel: +966551885676, Fax: +966 3 8584331, E-mail:amro9992000@yahoo.com
}

\begin{abstract}
Split air conditioning units are usually used for small and medium scale residential buildings. Therefore, more energy efficiency and lower cost are needed along with reliable control for the air conditioning units. An experimental investigation has been carried out to study the performance of a direct expansion air conditioning $(\mathrm{A} / \mathrm{C})$ unit having a variable speed condenser fan. The modulation of heat rejection airflow has been controlled with the outdoor air temperature via a Proportional Integral Differential (PID) controller. The control algorithm allows increasing the speed of condenser fan with the increase of outdoor air temperature and vice verse. The maximum rated air flow of the fan is $0.43 \mathrm{~m} 3 / \mathrm{s}$ at $42^{\circ} \mathrm{C}$ outdoor air temperature and the minimum is $0.28 \mathrm{~m} 3 / \mathrm{s}$. To facilitate variation of refrigerant flow rate according to the evaporator load, the traditional capillary tube was replaced with a suitable thermostatic expansion valve and liquid refrigerant reserve. The influence of condenser airflow and its temperature on the A/C unit performance and compressor power consumption has been investigated and presented at different evaporator cooling load. It has been found that a $10 \%$ reduction in compressor power consumption is achieved by increasing the condenser air flow by about $50 \%$.
\end{abstract}

Keywords: Split air conditioners, A/C unit performance, Variable speed condenser fan.

\section{Nomenclature}

COP coefficient of performance

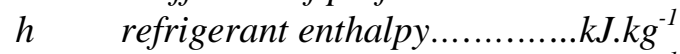

$m_{\text {ref }}$ refrigerant flow rate.............. $\mathrm{kg} . \mathrm{s}^{-1}$

$P \quad$ pressure............................ $\mathrm{kPa}$

$T_{e v} \quad$ evaporation temperature.......... ${ }^{\circ} \mathrm{C}$

\section{Introduction}

Energy saving is the practice of decreasing the quantity of energy used. It may be achieved through efficient energy use or by reducing the consumption of energy services [e.g. 1-3]. Air conditioning units are usually used for small and medium scale residential buildings. The amount of energy consumed by air conditioners, refrigerators and water heaters is increasing rapidly, since the consumed power by air conditioners occupies about $20 \%$ of the total power consumption. The improvement of refrigeration cycle performance can be done by lowering the compressor power consumption, increasing the condenser heat rejection capacity or reducing the difference between condenser and evaporator pressures.

A. Benamer and D. Clodic [4] offered a method for the comparison of energy consumption of variable and fixed speed scroll compressor in a refrigeration system. They showed that the lower the heat load, the higher the energy savings associated with variable speed. Also, variable speed compressor generates up to $40 \%$ savings in power consumption. S. Hu and B. Huang [5] presented a high efficiency split residential water-cooled air conditioner that utilizes cellulose pads as a filling material of the cooling tower. They showed that the water cooled condenser results in decreasing the compressor power consumption from 1.189 to 1.02 $\mathrm{kW}$ and the cycle COP is improved from 2.96 to 3.45. S. Wang et al. [6] presented a split air conditioner with a hybrid equipment of energy storage and water heater all year around. In summer, ice storage coils work as evaporator. In winter, energy storage tank absorbs the condenser heat to store heat during the heating process. They obtained around $28 \%$ increase in cooling capacity and $21.5 \%$ improvement in the COP. F. Yu and K. Chan [7] showed how the COP of air-cooled chillers can be improved by modulating heat rejection airflow via variable speed condenser fans. They introduced an algorithm that makes use of a set point of 
condensing temperature to determine the number and speed of condenser fans staged to provide the airflow required for any given heat rejection. Also, in order to achieve maximum COP under condensing temperature control with variable speed condenser fans, the set point of condensing temperature should be adjusted based on the chiller load together with the outdoor temperature. Potential energy saving for using water cooled air conditioner in residential building has been illustrated by $\mathrm{H}$. Chen et al. [8]. A split air conditioner with air and water cooled options was set up for experimental study at different indoor and outdoor conditions. The overall energy saving were estimated to be around $8.7 \%$ of the total electricity consumption.

Recently, T. Mahlia and R. Saidur [9] reviewed requirements and specifications of various international test standards for testing and rating of room air conditioners and refrigerators sacking for efficiency improvement of these appliances. Also, M. Jiang et al [10] evaluated the influence of condensing heat recovery on the dynamic behavior and performance of air conditioners. They showed that the condensing heat recovery has a negative effect on the cooling capacity at the start of the heat recovery process, while the average COP of the system is improved.

As shown in the previous literature, variable speed condenser fans have been handled for a large scale (i.e. chiller). The main objective of this study is to investigate the effect of condenser heat rejection modulation, via a variable speed fan, on the energy consumption and on the performance of a residential air conditioner. The speed of condenser fan is simultaneously controlled with the outdoor air temperature. The characteristics of refrigeration cycle that served by a thermostatic expansion valve will be presented at different indoor and outdoor temperatures at the steady state operation condition.

\section{Experimental apparatus and procedure}

A split type, $2.64 \mathrm{~kW}$ nominal capacity, air conditioner using R-22 was employed to exam the modulation of condenser heat rejection and its effect on the conditioner performance. The conditioner contains the basic components of a vapor compression system: a compressor, a condenser, a capillary tube, an evaporator and such attachments as filter/dryer and fans. The indoor unit includes a DX evaporator with copper tubes and aluminum fins, a fan and a capillary tube. The outdoor unit includes a constant speed rotary compressor and an aluminum finned-plate condenser that is provided with a constant speed propeller fan. The cooling output has ON/OFF control in accordance with the indoor set point temperature.

The normal method of adjusting the refrigerant mass flow in the evaporator is to add an expansion valve and an accumulator to the system. Therefore, a thermostatic expansion valve (with 0-1 orifice) and $1 \mathrm{~kg}$ liquid refrigerant accumulator have been installed in the refrigeration cycle. The condenser fan was employed to extract the room air through a foam duct and discharge it outside the room as shown in Photo 1, where Photo 2 shows the evaporating unit. Electric heaters were installed in the path of entering air to evaporator and condenser. Each heater was connected with a variable capacity transformer to control the heater power.

The refrigeration cycle of the conditioner was provided with controlling and measuring devices at the key locations of cycle. A schematic diagram of the experimental apparatus is shown in Fig. 1.

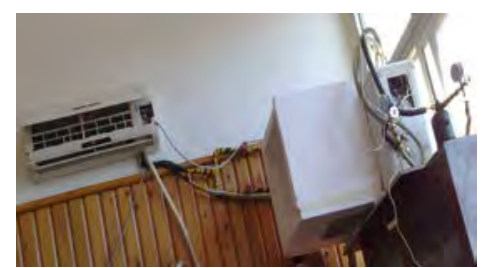

Photo 1: Condensing unit

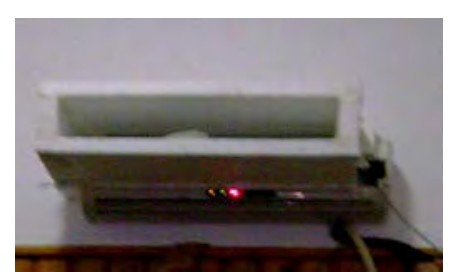

Photo 2: Evaporating unit 


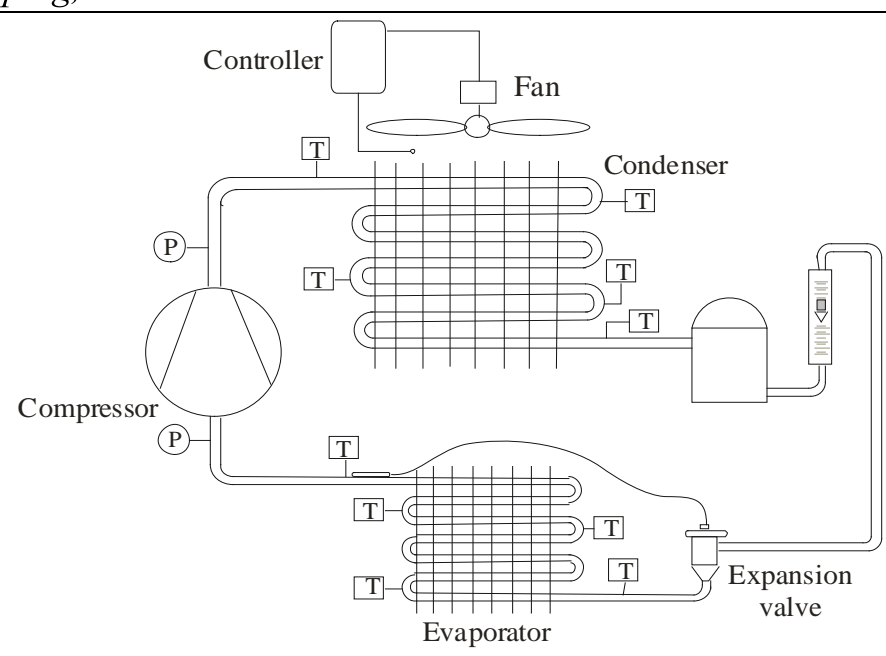

Fig. 1 A schematic view of the experimental apparatus

The temperature was measured via a type-T thermocouple with a maximum uncertainty of \pm $0.2^{\circ} \mathrm{C}$. Thermocouples were placed at the inlet and outlet of the evaporator and condenser. Also, thermocouples were installed along the tube length of the evaporator and condenser to determine the condensation and evaporation temperatures. The thermocouple junctions were soldered at the outer surface of the tubes and the thermocouple wires were connected to a digital thermometer. The condition of air at the inlet and outlet of each of evaporator and condenser was measured by means of a digital humidity/temperature meter with $1 \%$ accuracy of relative humidity and \pm 0.1 accuracy of dry bulb temperature. The liquid refrigerant mass flow rate was measured by a calibrated flowmeter with a maximum uncertainty of $\pm 0.5 \mathrm{~kg} / \mathrm{hr}$. A digital wattmeter with $\pm 1 \%$ reading uncertainty was provided to measure the compressor power consumption.

A Proportional Integral Derivative (PID) controller was used to control the speed of condenser fan. The controller had been connected with a temperature sensor, thermistor (LM35), which was positioned inside the foam duct at the front of condenser. When the condenser inlet air temperature is increased above the desired set point, the condenser fan speed is increased and vice verse. The velocity of air at the inlet condenser coil was measured via a digital vane anemometer with $0.1 \mathrm{~m} / \mathrm{s}$ accuracy, where the air velocity inside the condenser duct was ranged from 1.25 to $1.9 \mathrm{~m} / \mathrm{s}$.

It is worth mentioning that the room temperature was maintained at $24-26{ }^{\circ} \mathrm{C}$ during the experiments. All test runs were performed in an identical manner and at the steady state condition.

\section{Data reduction}

As mentioned, the air velocity $(\mathrm{m} / \mathrm{s})$ inside the condenser duct is measured via a vane anemometer and the rate of air flow $\left(\mathrm{m}^{3} / \mathrm{s}\right)$ is calculated by multiplying the duct cross section into the average air velocity. The evaporator cooling capacity, $\mathrm{Q}_{\mathrm{ev}}$, can be calculated as:

$\mathrm{Q}_{\mathrm{ev}}=\mathrm{m}_{\mathrm{ref}}\left(\mathrm{h}_{1}-\mathrm{h}_{4}\right)$

Where: $h_{1}, h_{4}$ are enthalpies of the refrigerant at evaporator inlet and outlet, respectively $(\mathrm{kJ} / \mathrm{kg})$. The common approach in determining the refrigeration cycle performance is to use the coefficient of performance, COP, depending on the compressor power consumption as;

$\mathrm{COP}=\mathrm{Q}_{\mathrm{ev}} / \mathrm{W}_{\mathrm{comp}}$ 


\section{Results and discussion}

The performance of the refrigeration cycle is a result of the balance between the four essential cycle components. When the outside ambient temperature varies, it affects the performance of the condenser, which in turn, affects the performance of the evaporator, expansion device and the compressor. The affecting parameters that influence the conditioner performance have been considered for illustration. Also, the modulation of condenser heat rejection airflow and its effect on the conditioner performance has been presented.

\subsection{Effect of evaporator inlet air temperature}

The refrigeration load of indoor unit may vary due to several reasons, such as the variation of ambient temperature. The influence of evaporator entering air temperature (return air temperature) on the evaporating temperature and evaporator cooling capacity, $\mathrm{Q}_{\mathrm{ev}}$, is presented in Fig. 2. It is observed in this figure that higher cooling capacity is achieved at $26^{\circ} \mathrm{C}$ which is the design operation condition recommended by manufacturers. As the inlet air temperature increases the evaporating temperature increases and the cooling capacity decrease.

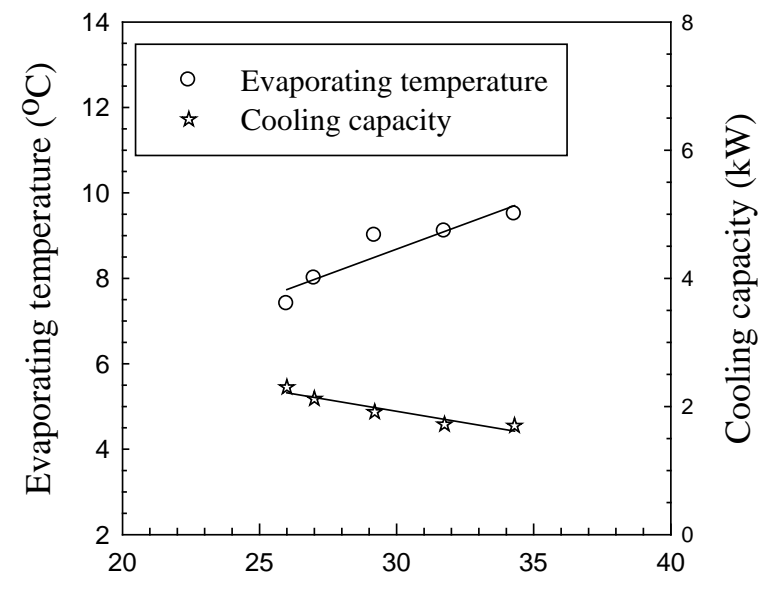

Evaporator inlet air temperature $\left({ }^{\circ} \mathrm{C}\right)$

Fig.2 Variation of evaporator entering air temperature with evaporating temperature and evaporator cooling capacity

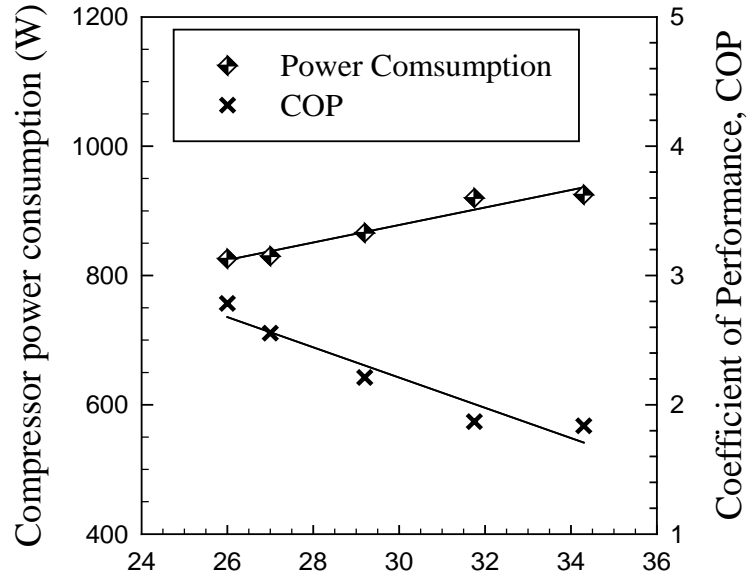

Evaporator inlet air temperature $\left({ }^{\circ} \mathrm{C}\right)$

Fig.3 Effect of evaporator inlet air temperature on compressor power consumption and cycle COP

The reduction of $\mathrm{Q}_{\mathrm{ev}}$ is about $25 \%$, when the inlet air temperature increased from 26 to $35^{\circ} \mathrm{C}$. This reduction in $\mathrm{Q}_{\mathrm{ev}}$ is referred to the evaporator starving which reduces the heat transfer coefficient in evaporator, since there is no sufficient refrigerant to accommodate the heat load. Here, it should be mentioned that the degree of superheating was varying from 5 to $9{ }^{\circ} \mathrm{C}$ and the corresponding mass flow rate of the refrigerant varied from 0.0106 to $0.0133 \mathrm{~kg} / \mathrm{s}$. Also, the degree of subcooling was varying from 2 to $3{ }^{\circ} \mathrm{C}$. Fig. 3 reveals that when the inlet air temperature increases the compressor power consumption increases causing a reduction in the coefficient of performance of the cycle. The increase of power consumption is about $12 \%$, while the reduction of COP is about $35 \%$.

\subsection{Effect of condenser inlet air temperature}

The effect of condenser inlet air temperature on the cycle performance is shown in figures 4 and 5.The temperature of air entering the condenser was varied by heating the supply air to the desired temperature. During these experiments, the ambient temperature was kept constant at $26{ }^{\circ} \mathrm{C}$ and the speed of condenser fan was constant which gives $0.28 \mathrm{~m}^{3} / \mathrm{s}$ of air. It is seen from Fig. 4 that the condensation temperature increases as the inlet air temperature increases, 
as expected, and the cooling capacity decreases with the increase of condenser temperature. This reduction in cooling capacity is due to the increase of evaporation temperature which is accompanied with the condenser temperature, since the compressor has a constant speed. The reduction of cooling capacity is about $32 \%$ as the condensing temperature increased by $17 \%$. Fig. 5 shows the variation of compressor power consumption and the cycle COP with the condensation temperature. The increase in condensing temperature, so thus the condenser pressure and the pressure ratio, leads to an increase in power consumption and a decrease in the cycle COP. The power consumption is increased by $36 \%$ and the reduction in COP is about $45 \%$ as shown in the figure.

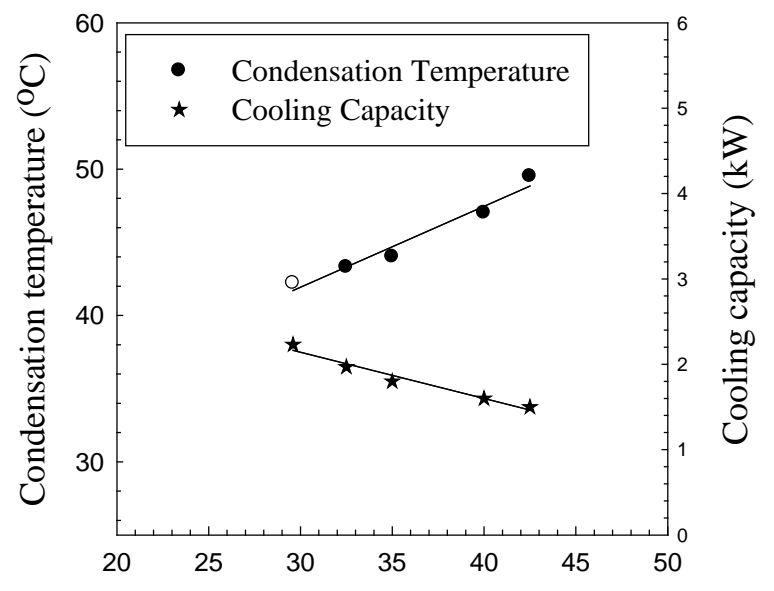

Condenser inlet air temperature $\left({ }^{\circ} \mathrm{C}\right)$

Fig.4 Variation of condenser entering air temperature with condensing temperature and evaporator cooling capacity

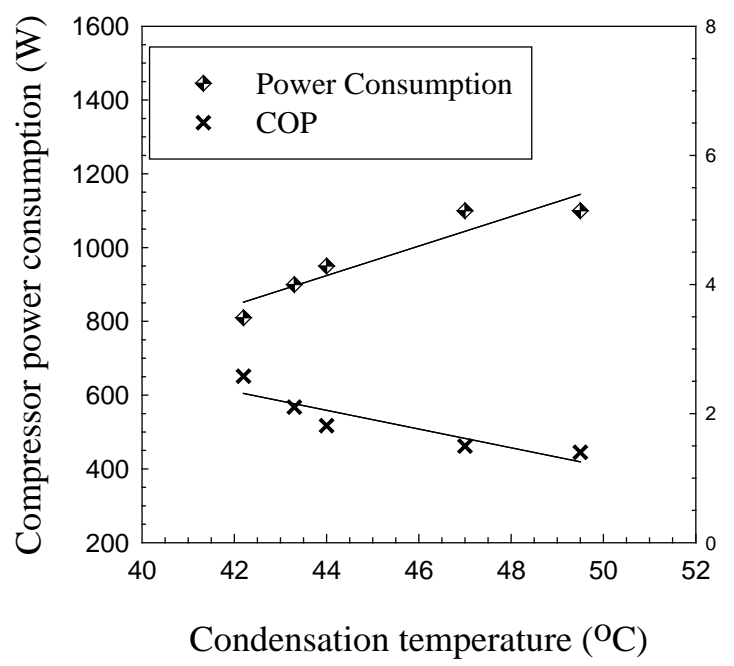

Fig.5 Effect of condensation temperature on compressor power consumption and cycle COP

\subsection{Modulation of condenser air flow at constant inlet air temperature}

During these experiments, the temperature of air, which cools the condenser, was kept constant at $36^{\circ} \mathrm{C}$ and the airflow through the condenser was varied by controlling the speed of fan manually. Although the increased heat rejection airflow causes the additional fan electric demand, the decreased condensing temperature results in a considerable reduction in compressor electric demand. This is shown in Fig.6, as the rate of air flow increases from 0.28 to $0.43 \mathrm{~m}^{3} / \mathrm{s}$ the condensing temperature decreased by about $8 \%$ and the corresponding reduction in compressor power consumption is about $10 \%$. These findings indicate that the compressor power depends on how condenser fan is controlled to provide the heat rejection airflow required for any given cooling capacity.

\subsection{Modulation of condenser air flow at different inlet air temperature}

The condensing temperature can be controlled at a minimum point by modulating the heat rejection airflow continuously. During these experiments, the condenser fan speed was varied according to the condenser inlet air temperature that represents outdoor air temperature. To show the effect of variable air flow for improving condenser heat rejection, a comparison between constant and variable fan speed has been presented in Figs. 7-9. Fig.7 illustrates the variation of condensing temperature with the inlet air temperature for constant and variable airflow. 


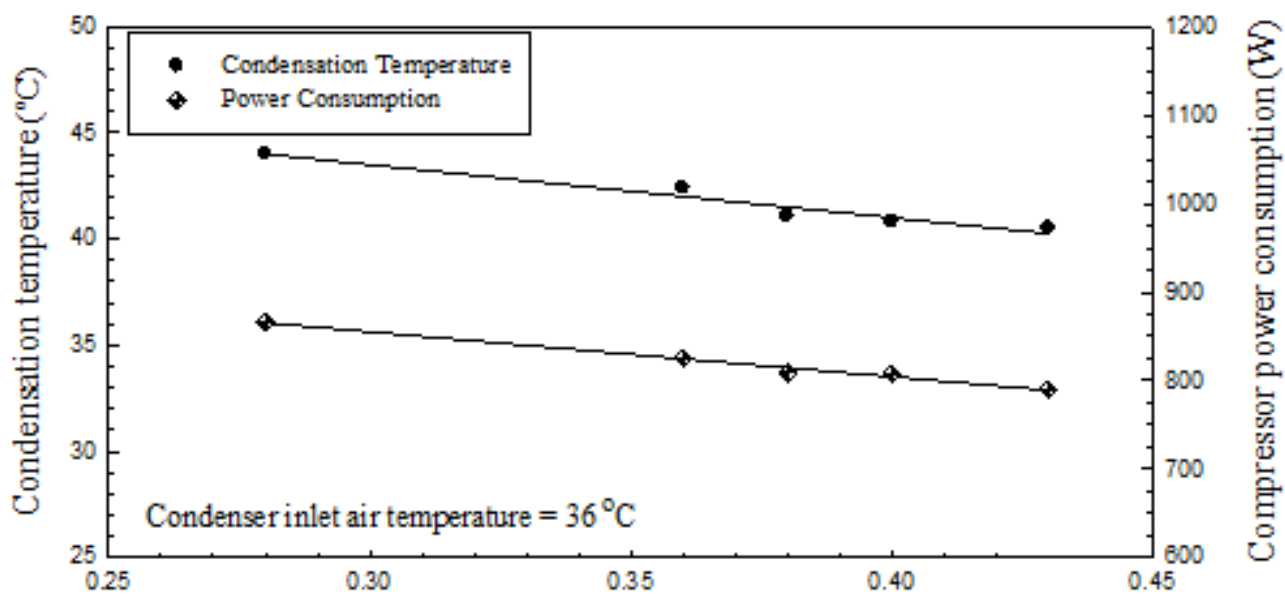

Air flow rate of condenser cooling $\left(\mathrm{m}^{3} / \mathrm{s}\right)$

Fig.6 Variation of condenser airflow with condensation temperature and compressor power consumptic

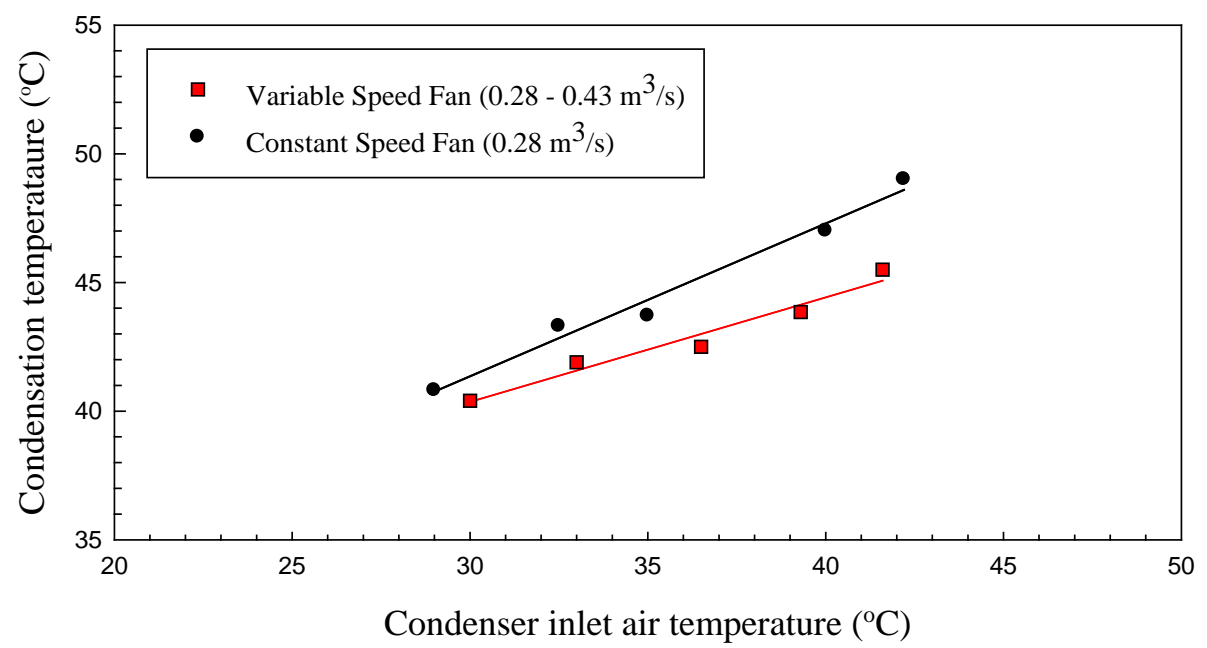

Fig.7 Variation of condensing temperature with condenser inlet air temperature for constant and variable airflow

As expected, by increasing the rate of airflow an improvement in condenser heat rejection is observed during which the condensing temperature has been reduced by $7 \%$ at $42^{\circ} \mathrm{C}$ inlet air temperature as shown in figure. The corresponding reduction in compressor power consumption is recorded in Fig.8. It is seen from this figure that at $42^{\circ} \mathrm{C}$ inlet air temperature the power consumption has been reduced by about $15 \%$, while at $36^{\circ} \mathrm{C}$ inlet air temperature the reduction is about $9 \%$. As mentioned earlier, the increase of heat rejection airflow needs an additional fan electric demand; however, this demand is small compared with the energy saved by the compressor. In addition, the max power required for condenser fan is only used at the peak of outdoor air. 


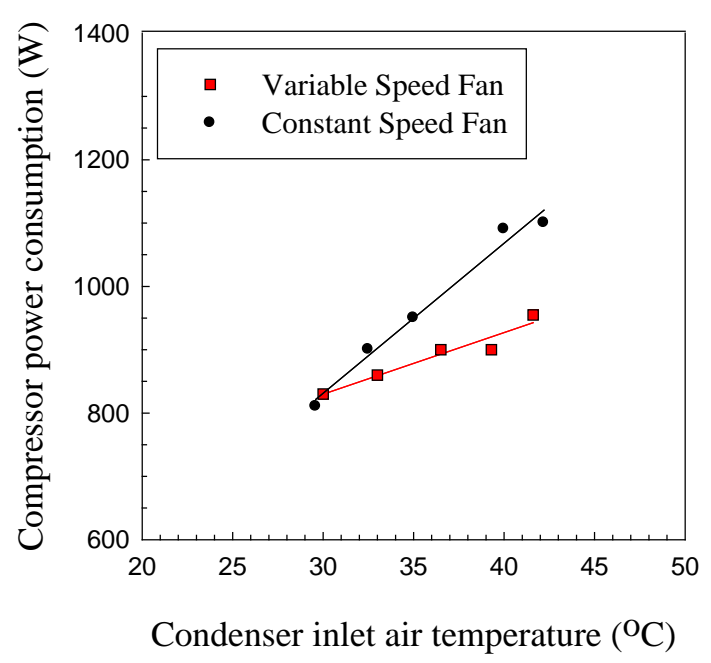

Fig.8 Variation of compressor power consumption with condenser inlet air temperature for constant and variable airflow

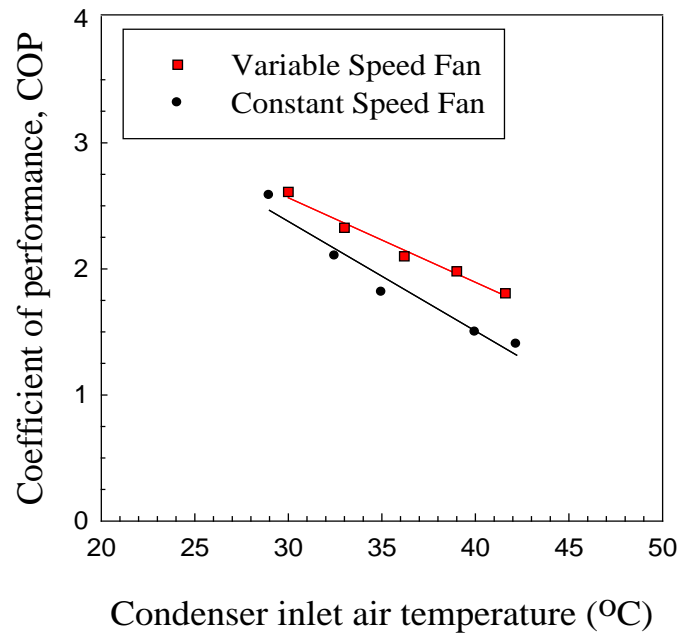

Fig.9 Variation of cycle COP with condenser inlet air temperature for constant and variable airflow

Fig.9 reveals the coefficient of performance of the conditioner during constant and variable airflow for condenser cooling. It is seen in this figure that, the COP of the cycle decreases as the condenser inlet air temperature increases for both constant and variable airflow. Since the increase in compressor power consumption is higher than the increase of the evaporator cooling capacity, so the COP of the cycle decreases. On the other hand, an improvement, about $28 \%$, in the cycle COP is observed for variable condenser airflow due to the lower compressor power consumption.

To evaluate the energy saving due to the improvement of COP, shown in Fig. 9, the unit coefficient of performance is presented in Fig. 10. This performance coefficient includes the power consumption of the condenser fan and is defined as:

$\mathrm{COP}_{\mathrm{U}}=\mathrm{Q}_{\mathrm{ev}} /\left(\mathrm{W}_{\text {comp }}+\mathrm{W}_{\text {Fan }}\right)$

As Fig. 10 shows, the unit $\mathrm{COP}_{\mathrm{U}}$ for variable condenser fan is greater than that for constant speed fan. The profit payback of the present energy saving method can be calculated by the economic analysis. The retrofitting of the present conditioner will be handled in a future work

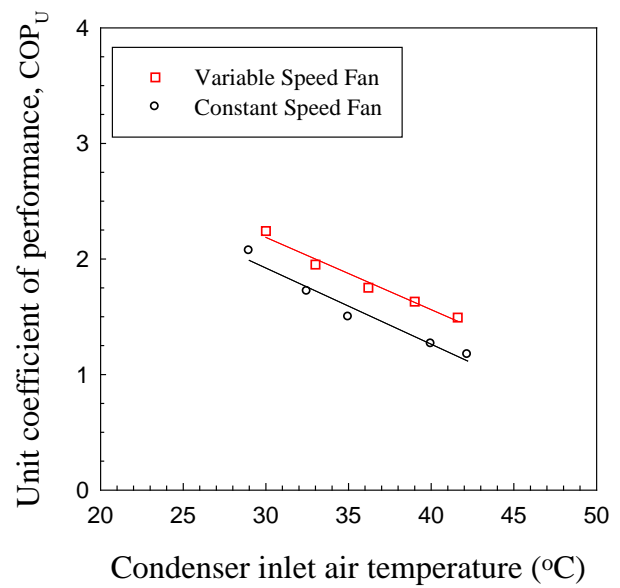

Fig.10 Variation of unit COP with condenser inlet air temperature

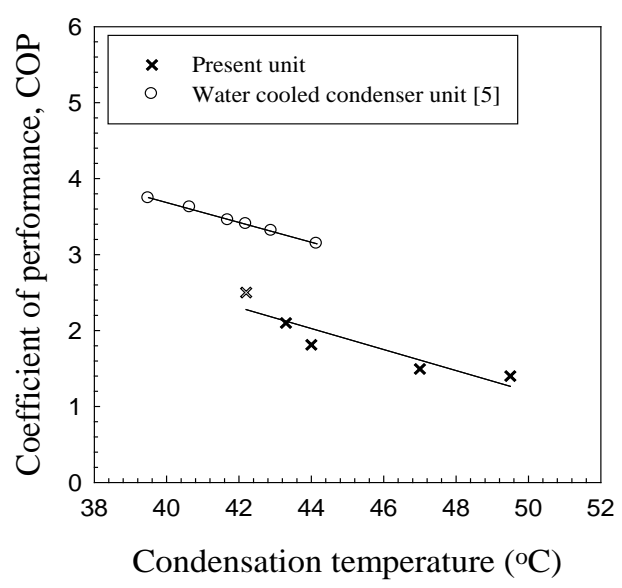

Fig.11 Comparison between the COP of the present conditioner and water cooled high performance conditioner in Ref [5]

The study is conducted to compare the present conditioner performance with the performance of water-cooled air conditioner in Ref [5]. As shown in Fig. 11, the COP of the water-cooled 
air conditioner is higher by about $35 \%$ than that for the present conditioner. This is due to the high heat capacity of water compared with the air.

\section{Conclusions}

From the above findings, it can be concluded that:

- The power consumption of the compressor was increased by $12 \%$ and the cooling capacity was decreased by $25 \%$, when rising the evaporator inlet air temperature from 26 to $35^{\circ} \mathrm{C}$.

- The cooling capacity of the evaporator was decreased by $32 \%$ when rising the condenser entering air temperature from 30 to $42^{\circ} \mathrm{C}$, while the compressor power consumption was increased by about $36 \%$.

- At constant inlet air temperature, a $10 \%$ reduction in compressor power consumption has been obtained when increasing the condenser cooling air flow by about 1.5 times.

- For variable speed condenser fan, it is found that the compressor power requirement has been reduced by $15 \%$ at $42^{\circ} \mathrm{C}$ condenser entering air temperature; while at $36^{\circ} \mathrm{C}$ the reduction is about $9 \%$.

- The use of variable speed condenser fan causes an increase in the COP of the conditioner by $28 \%$ at $42^{\circ} \mathrm{C}$ condenser entering air temperature.

Variable speed motor is recommended for the condenser fan with advanced control to accommodate the variation of outdoor air temperature for tracking and adjusting the condensing temperature.

\section{References}

[1] C.F. Gao, W.L. Lee, and Hua Chen, Locating Room Air-Conditioners at Floor Level for Energy Saving in Residential Buildings, Applied Thermal Engineering, 29, issues 2-3, 2009, pp. 310-316.

[2] E. Hajidavalloo, H. Eghtedari, Performance Improvement of Airp-Cooled Refrigeration System by Using Evaporatively Cooled Air Condenser, Int. Journal of Refrigeration, 33, issue 5, 2010, pp. 982-988.

[3] Zhenjun $\mathrm{Xu}$, Huaizhi Wu, Meiling Wu, Energy Performance and Consumption for Biogas Heat Pump Air Conditioner, Energy, 35, issue 12, 2010, pp. 5497-5502.

[4] A. Benamer, D. Clodic, Comparison of Energy Efficiency Between Variable and Fixed Speed Scroll Compressors in Refrigeration System, Proceedings of technological innovations in refrigeration in air conditioning and in the food industry into third millennium, $8^{\text {th }}-9$ June, 1999, pp.1-8.

[5] S.S. Hu, B.J. Huang, Study of a High Efficiency Residential Split Water-Cooled Air Conditioner, Applied Thermal Engineering, 25, 2005, pp. 1599-1613.

[6] S. Wang, Z. Liu, Y. Li, K. Zhao and Z. Wang, Experimental Study on Split Air Conditioner with New Hybrid Equipment of Energy Storage and Water Heater All Year Round, Energy Conversion and Management, 46, 2005, pp. 3047-3059.

[7] F.W. Yu and K.T. Chan, Advanced Control of Heat Rejection Airflow for Improving the Coefficient of Performance of Air Cooled Chillers, Applied Thermal Engineering, 26, 2006, pp. 97-110.

[8] H. Chen, W.L. Lee and F.W. Yik, Applying Water Cooled Air Conditioners in Residential Buildings in Hong Kong, Energy Conversion and Management, 49, 2008, pp. 1416-1423.

[9] T. Mahlia and R. Saidur, A Review on Test Procedure Energy Efficiency Standards and Energy Labels for Room Air Conditioners and Refrigerator-Freezers, Renewable and Sustainable Energy Reviews, 14, Issue 7, 2010, pp. 1888-1900.

[10] M. L. Jiang, J. Yi Wu, Y. X. Xu and R. Z. Wang, Transient Characteristics and Performance Analysis of a Vapor Compression Air Conditioning System with Condensing Heat Recovery, Energy and Buildings, 42, Issue 11, 2010, pp. 2251-2257. 